\title{
Synthesis and characterization of hydroxyapatite-gelatine composite materials for orthopaedic application
}

\author{
A. Yanovska a, b, *, V. Kuznetsov a, b, A. Stanislavov ${ }^{\text {a }}$, E. Husak ${ }^{\text {a, b }}$, M. Pogorielov ${ }^{\text {b }}$, \\ V. Starikov ${ }^{\text {c, S. Bolshanina }}{ }^{\text {b }}$, S. Danilchenko ${ }^{\text {a }}$ \\ a Institute of Applied Physics, National Academy of Sciences of Ukraine, 58 Petropavlovskaya Str., 40000, Sumy, Ukraine \\ b Sumy State University, Ministry of Education and Science of Ukraine, 2 R. Korsakova Str., 40007, Sumy, Ukraine \\ ${ }^{\mathrm{c}}$ National Technical University "Kharkov Polytechnic Institute", 21 Frunze Str., 61002, Kharkov, Ukraine
}

\section{H I G H L I G H T S}

- Hydroxyapatite-gelatine composites with addition of $\mathrm{Ag}^{+}$and $\mathrm{ZrO}_{2}$ were obtained.

- Composites were synthesized in two ways: simple mixing and co-precipitation.

- Co-precipitation synthesis combined ultrasonic treatment and low concentration of gelatine.

- Obtained composites have different weight ratios of organic/inorganic components.

- Some composites are osteoconductive and all of them have high level of porosity (75-85\%).

\section{A R T I C L E I N F O}

\section{Article history:}

Received 26 March 2016

Received in revised form

4 August 2016

Accepted 6 August 2016

Available online 6 August 2016

\section{Keywords:}

Composite materials

Biomaterials

Chemical synthesis

Ultrasonic techniques

Precipitation

Fourier transform infrared spectroscopy (FTIR)

\begin{abstract}
A B S T R A C T
The composite materials based on hydroxyapatite (HA) and gelatine (Gel) with addition of silver and zirconium oxide were obtained. The study investigates a combination of low powered ultrasonic irradiation and low concentration of gelatine in the co-precipitation synthesis. These composites have different weight ratios of organic/inorganic components and may be synthesized in two ways: simple mixing and co-precipitation. Both of which were compared.

The estimation of porosity, in vivo testing, surface morphology and phase composition as well as the IR-analysis were provided. Hydroxyapatite was the main crystalline phase in obtained composites.

While around powdered HA-Gel composite the connective tissue capsule is formed without bone tissue formation, HA-Gel-Ag porous composite implantation leads to formation of new bone tissue and activation of cell proliferation. Addition of silver ions into composite material allows decreasing inflammation on the first stage of implantation and has positive effect on bone tissue formation. Some of the obtained composite materials containing silver or $\mathrm{ZrO}_{2}$ are biocompatible. bio-resorbable and osteoconductive with high level of porosity (75-85\%).
\end{abstract}

() 2016 Elsevier B.V. All rights reserved.

\section{Introduction}

Over 40 billions euro is annually spent on treatment of bone tissue diseases and traumas [1] and 50\% of these expenses are used for osteoplastic materials, implants and prostheses. These materials should have biocompatible and osteoconductive properties [2].

Porosity is an essential parameter that defines the properties of

\footnotetext{
* Corresponding author. Institute of Applied Physics, National Academy of Sciences of Ukraine, Petropavlovskaya Str. 58, Sumy, 40000, Ukraine.

E-mail address: biophy@yandex.ru (A. Yanovska).
}

obtained biomaterials. Solid conjunctive tissues are porous, e.g., a porosity of the cancellous bone is from 50 to $90 \%$ (pore size is near $1 \mathrm{~mm}$ in diameter) [3,4]. Porous scaffolds are rather widely applied for regeneration of the bone tissue due to migration of osteogenic cells that contribute to bone tissue growth. The scaffolds may be manufactured with addition of ceramic materials, metals, biopolymers and calcium phosphate based inorganic components like hydroxyapatite, which is a mineral constituent of the bone tissue [5].

Combination of organic and inorganic components [6] allows obtaining materials with maximum biocompatibility and osteoconductivity. In bone tissue calcium phosphates and collagen fibrils 
are successfully combined with collagen fibrils. Therefore, composite materials like hydroxyapatite/collagen are of special interest in the bone defect replacement [7].

Today, the composites with gelatine are of great concern among the researchers. Gelatine is a product of partial collagen hydrolysis [2]. But in contrast to the latter, it is more stable and exhibits less antigenicity, which allows gelatine to be applied as a component of biomaterials $[2,6,8]$. Gelatine is advantageous in its availability, low cost, biocompatibility and biodegradability [8-10]. Furthermore, gelatine is a polyampholyte with the cationic (13\% lysine and arginine), the anionic ( $12 \%$ glutamic and aspartic acid) and the hydrophobic groups ( $11 \%$ of the chain comprising leucine, isoleucine, methionine and valine) present in ratio 1:1:1. Other part of the chain contains glycine, proline and hydroxyproline (Fig. 1) $[8,10]$.

There are various methods of HA-gelatine composites preparation [11-17]: ultrasonic thermally assisted synthesis of nano hydroxyapatite [12], biomimetic precipitation [13]. But still the most popular method is hydroxyapatite precipitation into a gelatine gel or a matrix $[14,15]$. Limitation of the HA nanopowder dispersion method [16] is agglomeration of HA powder in a concentrated gelatine solution. This might cause difficulties for composite material formation with desirable structural features [17]. HA-gelatine composites preparation by co-precipitation from aqueous solutions with low concentrations of gelatine and addition of various components is understudied. Particularly promising is addition of antibacterial components [18] that allow reducing inflammation at the initial stage of implantation [19].

In this work, the composite materials based on carbonate HA and gelatine with addition of silver and zirconium (IV) oxide were synthesized by co-precipitation and dispersion method. Obtained samples were compared, structural features and morphology of the HA and gelatine based composites were determined. Potential bioactivity of the materials was evaluated in the in vivo experiments.

\section{Materials and methods}

\subsection{Materials and reagents}

The analytically grade reagents $\mathrm{Ca}\left(\mathrm{NO}_{3}\right)_{2} \cdot 4 \mathrm{H}_{2} \mathrm{O}, \mathrm{Na}_{2} \mathrm{HPO}_{4} \cdot 4 \mathrm{H}_{2} \mathrm{O}$, $\mathrm{NaHCO}_{3}, \mathrm{NaOH}, \mathrm{AgNO}_{3}, \mathrm{ZrO}_{2}$ and pharmaceutical gelatine by Zhengzhou Sino Chemical Co. Ltd, China, were used in the study.

\subsection{Synthesis of composite materials}

Carbonate hydroxyapatite, which is the main mineral component of a bone tissue [20], was used as an inorganic constituent of a composite material. It was synthesized by following equation:

$$
\begin{aligned}
& 9 \mathrm{Ca}\left(\mathrm{NO}_{3}\right)_{2} 4 \mathrm{H}_{2} \mathrm{O}+5 \mathrm{Na}_{2} \mathrm{HPO}_{4} 4 \\
& \mathrm{H}_{2} \mathrm{O}+\mathrm{NaHCO}_{3}+8 \mathrm{NaOH} \rightarrow \mathrm{Ca} 9 \mathrm{Na}\left(\mathrm{PO}_{4}\right)_{5} \mathrm{CO}_{3}(\mathrm{OH})_{2}+18 \\
& \mathrm{NaNO}_{3}+107 \mathrm{H}_{2} \mathrm{O}
\end{aligned}
$$

Gelatine was dissolved in water at $80^{\circ} \mathrm{C}$; then a synthesized $\mathrm{HA}$ and relevant quantity of additives (samples a, d, e) were added under ultrasonic treatment. The sample (a) contained 2.6\% HA, 0.9\% $\mathrm{ZrO}_{2}$, 5.5\% gelatine, $91 \% \mathrm{H}_{2} \mathrm{O}$; (d) $6.3 \% \mathrm{HA}, 1.8 \%$ gelatine, $0.9 \% \mathrm{ZrO}_{2}$, $0.01 \% \mathrm{Ag}, 90.99 \% \mathrm{H}_{2} \mathrm{O}$; (e) $7.2 \% \mathrm{HA}, 1.8 \%$ gelatine, $91 \% \mathrm{H}_{2} \mathrm{O}$. Component ratio in dry substance was as follows: a) $\mathrm{HA}-\mathrm{Gel}-\mathrm{ZrO}_{2}-$ $3 / 6 / 1$; b) HA-Gel - 2.15/1; c) HA-Gel-Ag - 2.15/1/0.01; d) HA-Gel$\mathrm{ZrO}_{2}-\mathrm{Ag}-7 / 1.99 / 1 / 0.01$; e) HA-Gel $-8 / 2$.

Composite materials (b, c) were prepared in situ by coprecipitation of gelatine and carbonate $\mathrm{HA}$ from aqueous solutions. The sample (b) contained $21.5 \% \mathrm{HA}, 10 \%$ gelatine, $68.5 \% \mathrm{H}_{2} \mathrm{O}$; (c) $21.5 \% \mathrm{HA}, 10 \%$ gelatine, $0.1 \% \mathrm{Ag}, 68.4 \% \mathrm{H}_{2} \mathrm{O}$, The sample (b) was synthesized according to a scheme in Fig. 2 (stage 1-3).

First solution was obtained by addition of $0.84 \mathrm{~g} \mathrm{NaHCO}_{3}$ to 0.1 M solution of $\mathrm{Ca}\left(\mathrm{NO}_{3}\right)_{2} \cdot 4 \mathrm{H}_{2} \mathrm{O}$ while stirring until completely dissolved. Gelatine was added during the synthesis of carbonate apatite: $5 \%$ gelatine solution $\left(\mathrm{t}=80^{\circ} \mathrm{C}\right)$ was added to $0.06 \mathrm{M}$ solution of $\mathrm{Na}_{2} \mathrm{HPO}_{4} \cdot 4 \mathrm{H}_{2} \mathrm{O}$ while stirring. Throughout the whole experiment the temperature was maintained at the same level (second solution). The obtained solution was added dropwise to the first solution under constant stirring and then $10 \mathrm{M}$ solution of $\mathrm{NaOH}$ was being added until $8.0 \mathrm{pH}$ was obtained.

The obtained product was a uniform fine composite that was divided into 2 parts ( $500 \mathrm{ml}$ each). $5 \mathrm{ml}$ of $\mathrm{AgNO}_{3}$ solution with $10 \mathrm{~g} \mathrm{~L}^{-1}$ concentration (sample $\mathrm{c}$ ) was added into the first part. The second part remained unchanged.

After that the obtained composites were rinsed with distilled water until pH 7.3 was reached. Ageing of the obtained composites in the solution was performed for $48 \mathrm{~h}$ at $22^{\circ} \mathrm{C}$. Then the samples were freeze-dried and, for comparison, the same samples were dried in the open air.

\subsection{Porosity and density determination}

Porosity was determined with a liquid displacement technique [21]. Ethanol was chosen as displacement liquid since it penetrates the open pores and causes no expanding or deformation [22].

A sample with known dry weight $(\mathrm{W})$ was immersed into a graduated cylinder with known volume $\left(\mathrm{V}_{1}\right)$ of ethanol added. The sample was pressed down for ethanol penetration and was left there for $24 \mathrm{~h}$. Total volume of the remained ethanol and soaked scaffold is marked as $\left(V_{2}\right)$ to denote liquid level in the cylinder. Volume difference $\left(V_{2}-V_{1}\right)$ is scaffold volume. A scaffold soaked

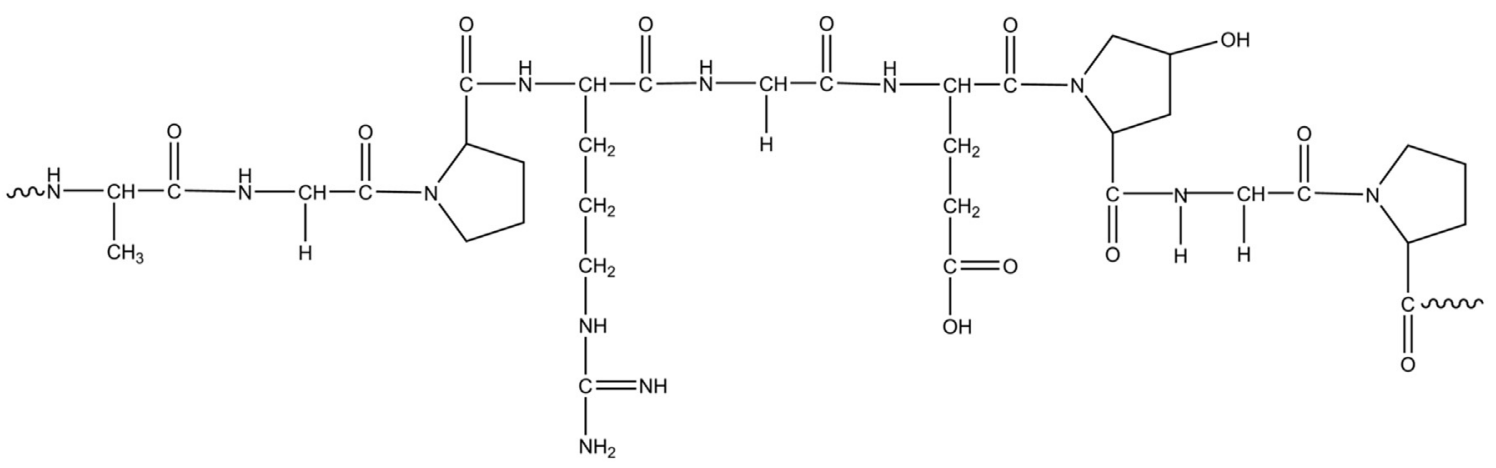

Fig. 1. Basic chemical structure of gelatine $[8,10]$. 


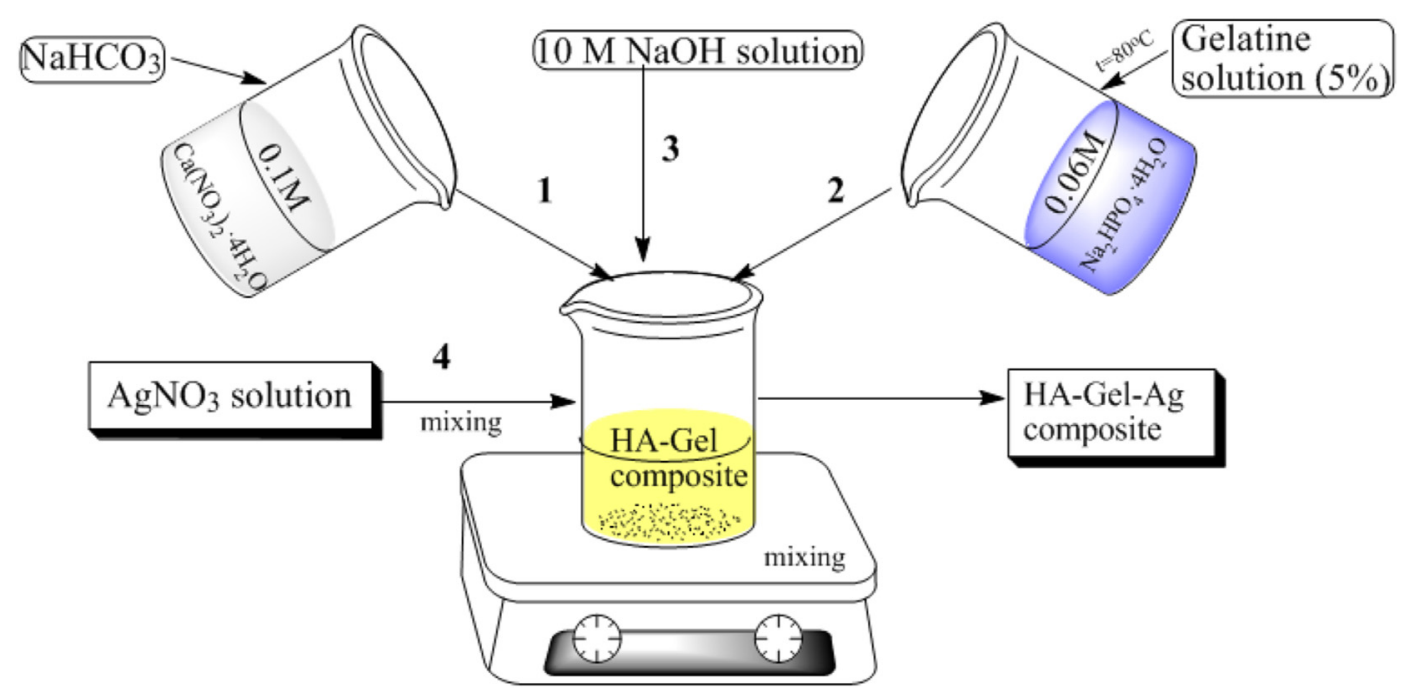

Fig. 2. The synthesis scheme of composite materials HA-Gel (b), and HA-Gel-Ag (c) obtained by co-precipitation from aqueous solutions.

with ethanol was taken from the graduated cylinder and volume of remained ethanol was marked as $\mathrm{V}_{3}$. Porosity was calculated by equation [23]:

$P(\%)=\frac{\left(V_{1}-V_{3}\right)}{\left(V_{2}-V_{3}\right)} \times 100$,

For density $(d)$ calculation of the obtained composites the equation [24] was taken:

$d=\frac{W}{\left(V_{2}-V_{3}\right)}$,

Calculated results are presented with mean square deviation that is calculated for three samples of each composite.

\subsection{Characterization techniques}

The morphology analysis of obtained composites was provided by scanning electron microscopy (REMMA-102, SELMI, Sumy, Ukraine), optical microscopy (Karl Zeiss Primo Star, Karl Zeiss Microimaging, GMBH, Germany) and digital camera (Canon PowerShot A1400).

The X-ray diffraction (XRD) analysis was carried out by the X-ray diffractometer DRON-4-07 (Bourevestnik, www.bourevestnik.ru) connected to a computer-aided system for experiment control and data processing. The $\mathrm{CuK} \alpha$ radiation was used (wavelength $0,154 \mathrm{~nm}$ ) with the Bragg-Brentano focusing method. Current and voltage of the X-ray tube were $20 \mathrm{~mA}$ and $40 \mathrm{kV}$, respectively. The scan was performed in a continuous registration mode with $0.02^{\circ}$ step and $1^{\circ} / \mathrm{min}$ scan speed in $2 \theta$ range of $10^{\circ}-60^{\circ}$. All experimental data were processed using the DifWin-1 program package (Etalon-TC, www.specord.ru). Phase identification was performed using JCPDS (Joint Committee on Powder Diffraction Standards) card catalog.

The qualitative phase analysis was performed with the reference intensity ratio (RIR) method [25] to determine the concentrations of crystallite phases. The method is based on the corundum number - the ratio of intensities of two main peaks of the studied phase and synthetic corundum in their two-component 50:50 mixture. If the main peak is overlapped, another one could be used with respect to its relative intensity. These values (corundum number and relative intensities) are available in the JCPDS card catalogue.

$$
C_{i}=\left(\frac{K_{i} I_{i}^{r e l}}{I_{i}} \sum_{i=1}^{n} \frac{I_{i}}{K_{i} I_{i}^{r e l}}\right)^{-1},
$$

where $C_{i}$ is the concentration of the i-phase, $K_{i}$ is the corundum number of the i-phase, $I_{i}$ is the intensity of the selected peak of the $\mathrm{i}$-phase, $I_{i}^{r e l}$ is the relative peak intensity of the i-phase.

The molecule structural components were identified by the Fourier IR-spectrometer "Spectrum One" (Perkin-Elmer, USA, 2003). The solid probes were pressed in $\mathrm{KBr}$ tablets and analyzed. Measurements and analysis of spectra were carried out with software of the device.

\subsection{In vivo study}

30 Wistar rats were used for experiments and housed in vivarium condition at Medical Institute of Sumy State University. Housing of the animals and all experimental procedures were carried out in accordance with the Directive 2010/63/EU of the European Parliament and of the Council as of 22 September 2010 on the Protection of Animals Used for Scientific Purposes. All materials were sterilized with ethanol (96\%) during $1 \mathrm{~h}$.

Animals were divided into 5 groups, 6 rats in each (a-e). After general anaesthesia (ketamine, $10 \mathrm{mg}$ per $1 \mathrm{~kg}$ ) the round bone defect was performed on medial surface of tibia with a dental drill $(ø 1.1 \mathrm{~mm}$ ) with perfusion of saline solution. Bone defect in animals of first group was filled with the composite powder materials (b), in other groups - by the spongy porous materials (a, c, d, e). Skin defect was sutured after operation and animals were put back into the vivarium.

The animals were euthanized by ketamine overdosing (70 mg per $1 \mathrm{~kg}$ ). The bone with defect was fixed in $10 \%$ formaldehyde and decalcified in a mixture which contained $45 \mathrm{ml}$ of formic acid, $5 \mathrm{ml}$ of formaldehyde and $45 \mathrm{ml} \mathrm{H}_{2} \mathrm{O}$. Then it was dried in alcohols of elevated concentrations and set into a paraffin wax. The $12 \mu \mathrm{m}$ thick sections were prepared and stained with haematoxylin and eosin. The specimens were investigated by a light microscope "OLYMPUS". Morphometric parameters were performed in "SEO ImageLab" software. 
Table 1

Measurement results of density and porosity for the HA and gelatine based composites.

\begin{tabular}{lll}
\hline Sample & Density, d $\left(\mathrm{g} \mathrm{cm}^{-3}\right)$ & Porosity, P (\%) \\
\hline a & $0.070 \pm 0.03$ & $80 \pm 0.03$ \\
b & $0.049 \pm 0.02$ & $80 \pm 0.03$ \\
c & $0.083 \pm 0.01$ & $75 \pm 0.02$ \\
d & $0.099 \pm 0.02$ & $75 \pm 0.02$ \\
e & $0.086 \pm 0.01$ & $80 \pm 0.01$ \\
\hline
\end{tabular}

\section{Results and discussion}

Measurement results of density and porosity for the HA and gelatine based composites are shown in Table 1. Calculated porosity of the composites is within $75-80 \%$, which corresponds to porosity of a spongy bone [26].

All values are presented with standard deviations. All experiments were performed at least three times and showed reliable reproducibility.

When $\mathrm{Ag}^{+}$ions were added during synthesis, density of composite materials increased. It is probably related to gelatine fixation with silver ions. Fig. 3 shows IR-spectra of composites (b, c) obtained by the co-precipitation method from the aqueous solutions since interaction between the components is possible in this type of synthesis.

In Fig. 3 the absorption peaks located at 1092 and $1033 \mathrm{~cm}^{-1}$ were originated from asymmetrical stretching $(v 3)$ of $\mathrm{PO}_{4}^{3-}$ and at 566 and $603 \mathrm{~cm}^{-1}$ were attributed to bending modes $(v 4)$ of $\mathrm{PO}_{4}^{3-}$, respectively [4,27]. The symmetric stretching modes ( $v 1$ and $v 2$ ) of $\mathrm{PO}_{4}^{3-}$ were also observed at around $961 \mathrm{~cm}^{-1}$, while a weak sharp peak at $3573 \mathrm{~cm}^{-1}$ corresponded to the stretching vibration of the lattice $\mathrm{OH}^{-}$ions [28].

In Fig. 3 c the $1658 \mathrm{~cm}^{-1}$ bands is the absorption of amide I [29]. Some $\mathrm{CO}_{3}^{2-}$ derived bands were observed at 1462 and $873 \mathrm{~cm}^{-1}$, respectively, which indicated that $\mathrm{CO}_{3}^{2-}$ can substitute $\mathrm{PO}_{4}^{3-}$ in the lattice of HA [28]. The peak at $2923 \mathrm{~cm}^{-1}$ corresponds to $\mathrm{O}-\mathrm{H}$ stretch carboxylic acids. In reference [29] authors reported that assignment at $1648 \mathrm{~cm}^{-1}$ corresponded to $\mathrm{N}-\mathrm{H}$ bend primary amines. Therefore, shift to $1658 \mathrm{~cm}^{-1}$ could be explained by the interaction of silver with $\mathrm{N}-\mathrm{H}$ group. However, in Fig. 3 (a) peak at $1645 \mathrm{~cm}^{-1}$ corresponds to $\mathrm{O}-\mathrm{H}$ band in carbonate apatite. Thus, the interaction between silver and gelatine could be possible but cannot be confirmed.

Considerable discrepancies in the composite densities are observed in terms of the drying techniques applied. When freezedrying is applied, the structure of composites becomes like porous sponge that is dense and soft $(a, c, d, e)$. Sometimes they are decomposed onto a powder (b) after the freeze-drying and hence become dense and compact. Morphology of the obtained material is shown in Fig. 4.

From general view of obtained composite materials (Fig. 4.1a-1e) is seen that most of them are of porous ( $1 \mathrm{a}, \mathrm{c}, \mathrm{d}$ ) or laminated structure $(1 \mathrm{e})$. Micrographs at magnification $\times 4$ (Fig. 4.2a-e) and $\times 10$ (Fig. 4.3a-e) were made by optical microscopy. SEM micrographs (Fig. 4.4a-e) were made at magnification $\times 50$. Porous structure is preferred for ingrowths of a newly formed bone tissue.

XRD spectra are shown in Fig. 5 with the bar chart corresponding to hydroxyapatite (JCPDS 84-1998). In samples $a$ and $d$ the additional phase of zirconium oxide (JCPDS 74-815) is also present. The symbol $\bullet$ marks the main peak of zirconium oxide. The crystallinity of HA decreases with the reduction of its amount in the samples. It should be mentioned that the superposition of main HA peaks ( $2 \theta$ range of $31^{\circ}-35^{\circ}$ ) is better resolved in case of the sample $e$ than that of pure HA (sample $f$ ).

There are some limitations in the experimental protocol. As crystallinity of the analyzed samples is low, the obtained X-ray diffraction spectra are not of sufficient resolution to provide complex characterization of apatite structure, e.g., it is impossible to estimate average crystallite sizes in the majority of crystallographic planes or to calculate HA unit cell parameters with sufficient accuracy for some of the samples. The presence of $\mathrm{Ag}$ could not be confirmed by the XRD because of its small concentration $(0.01 \%)$ to prevent the toxic effect on the organism. Further investigations should include the separation of size-strain contributions to the

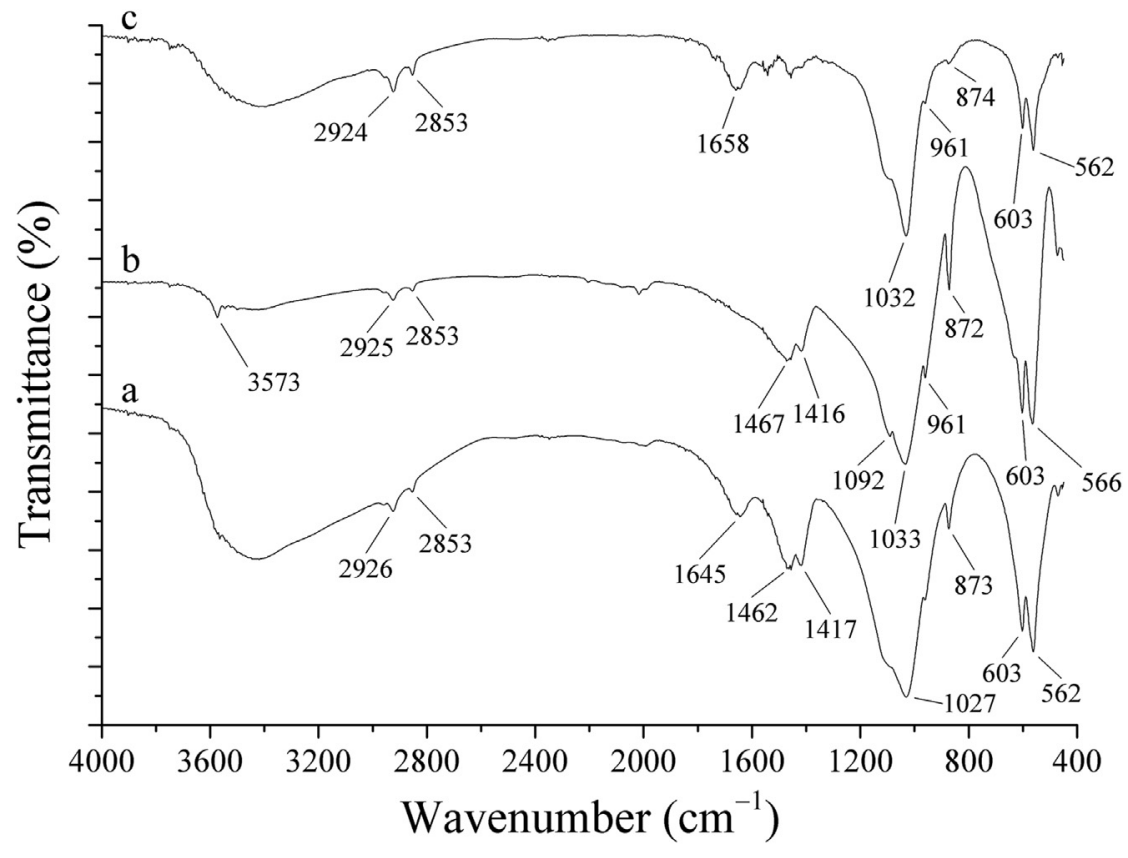

Fig. 3. IR-spectra of a) carbonate apatite; b) carbonate containing HA-Gel; c) HA-Gel-Ag. 


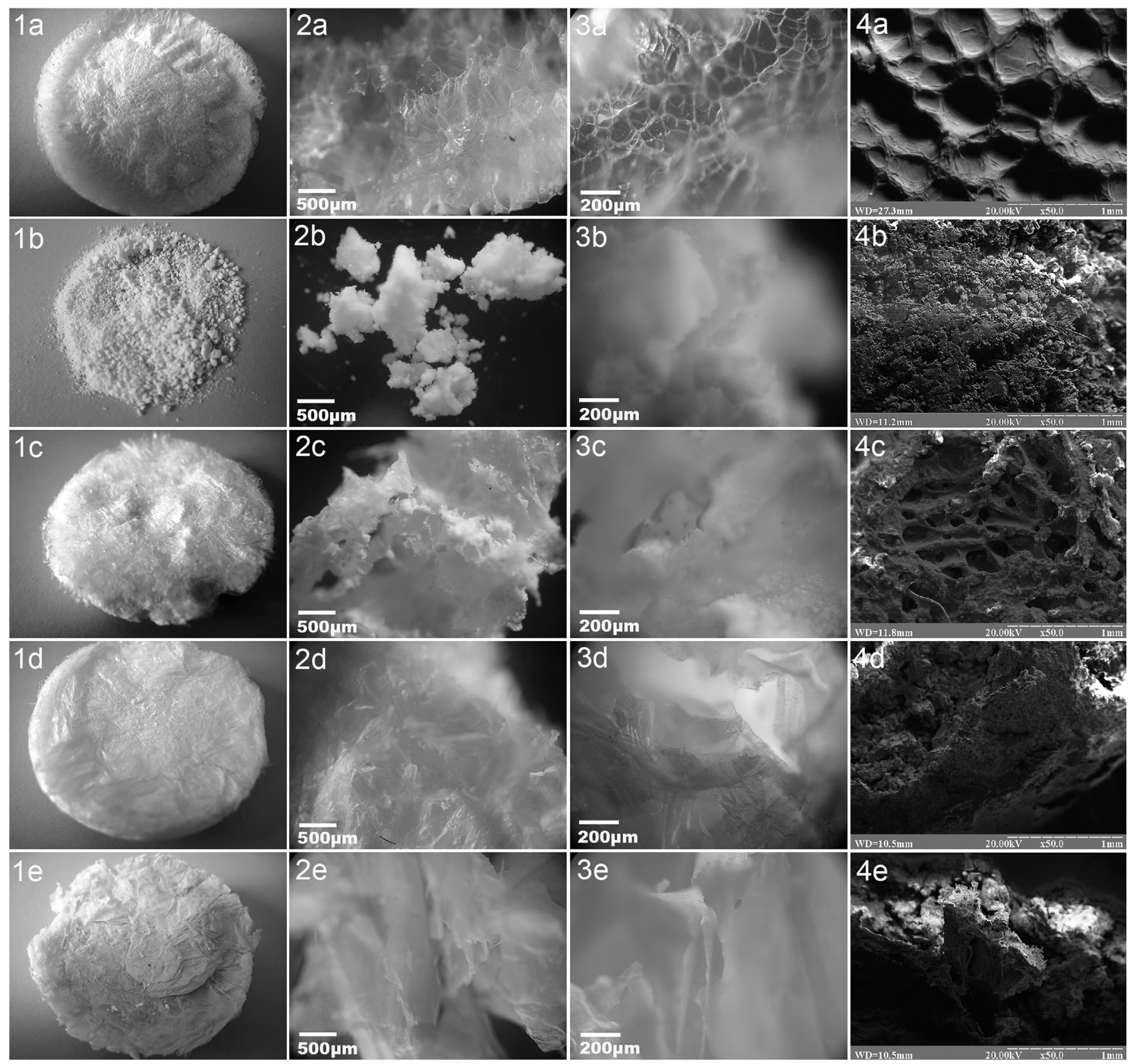

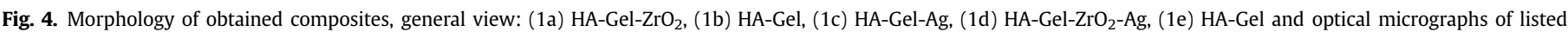
composite materials at magnification $\times 4(2 a-2 e)$ and at magnification $\times 10(3 a-3 e)$. SEM micrographs $(4 a-4 e)$.

peak broadening due to the presence of $\left(\begin{array}{lll}0 & 0 & 2\end{array}\right)$ and $\left(\begin{array}{lll}0 & 0 & 4\end{array}\right)$ peaks on XRD spectra. Moreover, annealing of the samples in order should help to determine whether the initial apatite is calcium deficient or not.

The form of the multiplet at $\sim 33^{\circ} 2 \theta$ could be explained by the presence of gelatin, which decreases the crystallinity of hydroxyapatite $[30,31]$.

Calculated crystalline phases concentrations are presented in Table 2.

Crystallite sizes in $\left(\begin{array}{lll}0 & 0 & 2\end{array}\right)$ plane of HA were calculated using Scherrer equation (Table 3 ) except for the sample $a$ due to its poor crystallinity.

The obtained data show mainly the decrease of crystallite sizes of HA with the increase of the concentration of other components.
These results are in a good agreement with work [32] confirming that the addition of gelatine leads to the decrease of crystallinity, which is indicated by the crystallite sizes and X-ray diffraction spectra.

Some authors [33] claimed that $0.1 \mathrm{mg} / \mathrm{g}$ was a health advisory level for silver. Ionic silver given as $\mathrm{AgNO}_{3}$ was lethal to lab mice and rabbits at 13.9 and $20 \mathrm{mg} / \mathrm{kg}$ body weight, respectively. Toxicity of silver resulting from drinking water ingestion in rats is $400 \mu \mathrm{g} \mathrm{L}^{-1}[34,35]$.

Cytocompatibility, osteoinduction and bone mineralization (ALP and osteocalcin assay) of $\mathrm{HA}-10 \% \mathrm{Ag}$ composites were illustrated [36]. Our composite materials contain $0.01-0.1 \%$ of silver. Such amount of silver is non-toxic but has antibacterial activity and decreases inflammation at the initial stage of implantation. 


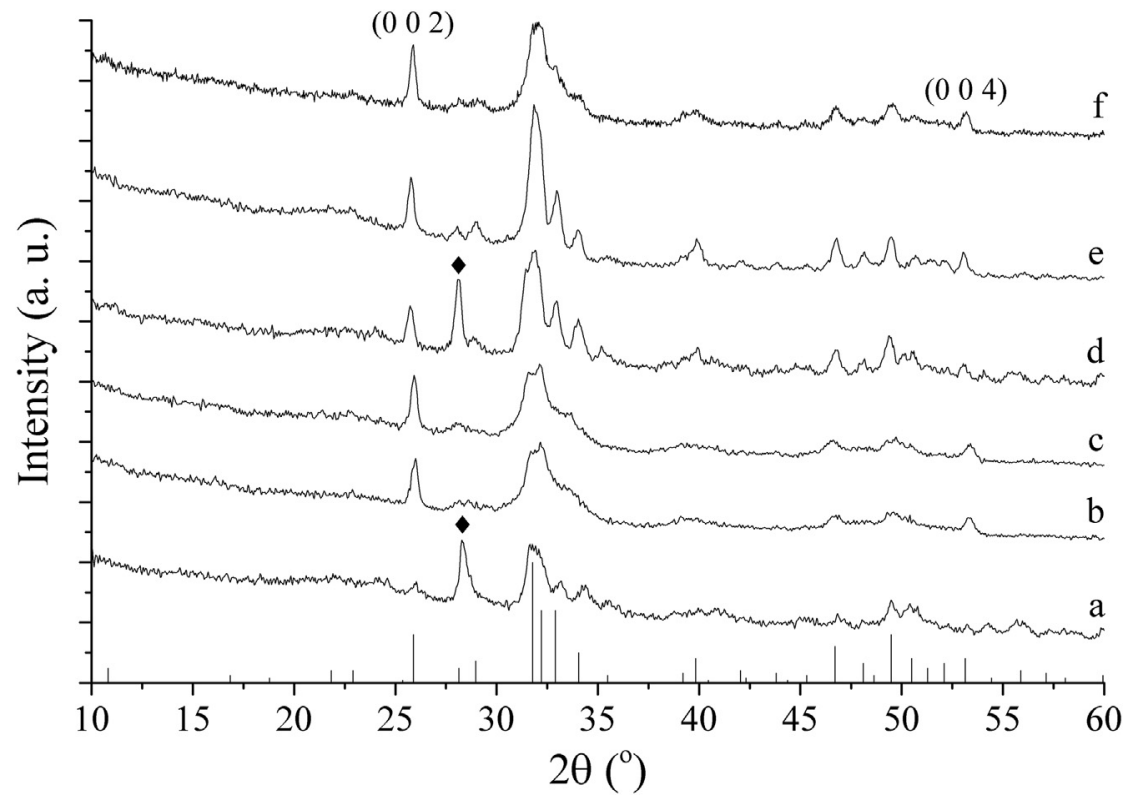

Fig. 5. XRD patterns of synthesized composites: a) $\mathrm{HA}-\mathrm{Gel}_{-} \mathrm{ZrO}_{2}$; b) $\mathrm{HA}-\mathrm{Gel}$; c) $\mathrm{HA}-\mathrm{Gel}-\mathrm{Ag}$; d) HA-Gel-ZrO $2-\mathrm{Ag}$; e) $\mathrm{HA}-\mathrm{Gel}$, f) pure $\mathrm{HA}$.

Table 2

Phase concentrations according to the RIR method.

\begin{tabular}{lll}
\hline Phase concentration, \% & \multicolumn{2}{l}{ Samples } \\
\cline { 2 - 3 } & $\mathrm{a}$ & $\mathrm{d}$ \\
\hline $\mathrm{HA}$ & 70.6 & 86.6 \\
$\mathrm{ZrO}_{2}$ & 29.4 & 13.4 \\
\hline
\end{tabular}

Table 3

Crystallite sizes of HA after Scherrer.

\begin{tabular}{lllllll}
\hline Samples & a & b & c & d & e & f \\
Crystallite sizes, nm & - & 20.5 & 23.2 & 22.8 & 24.7 & 29.5 \\
\hline
\end{tabular}

Zirconium oxide falls into the category of bioinert materials [36]. Zirconium materials are widely used as implant materials. Zirconium compounds are generally considered to be of low toxicity. In vitro tests have shown that zirconia has a lower toxicity than titanium oxide. Their cytotoxicity, carcinogenicity, mutagenic or chromosomal alterations in fibroblasts or blood cells has not been observed [37].

The histological analysis of bone tissue was performed after 21 days of the implantation and is presented in Fig. 6. Composite material (b) was implanted as a powder, while samples (a, c, d, e) as a porous sponge. After 21 days since implantation the composite materials (a) and (c), the defect was filled with newly-formed bone tissue with irregular staining as compared to the hosting bone. There was a network of vessels visible inside the new bone tissue and red bone marrow cells filling intertrabecular spaces. The newly-formed tissue was rich in osteoblasts indicating active remodelling process [38].

The connective-tissue capsule was formed around sample (b) within 21 days after implantation. It was made by random oriented collagen fibrils and had thickness of $28.65 \pm 14.55 \mu \mathrm{m}$. There were some vessels and fibroblasts, lymphocytes and neutrophiles visualized in the connective-tissue capsule and some macrophages near the area contacting with the implanted material. There was no tissue ingrowth and cells migration into the implant pores, which indicated the absence of osteoconductive properties needed for successful implant ingrowths in the bone tissue [39].

Results of material 1 (d) implantation are presented in Fig. 6 (d and 1d). Partial biodegradation of material and formation of the connective-tissue capsule were observed after 21 days of implantation. Pores of the material were filled with a connective tissue that had a high density of leucocytes and macrophages. The newlyformed bone tissue was visualized around remnant of the composite material. The vascular network that complicates regeneration process was not observed. Since angiogenesis is connected with the bone healing process, its suppression leads to decelerated healing [40].

The composite material (e) was completely substituted by the newly-formed bone tissue up to 21 days after implantation. New bone tissue had irregular staining that may indicate incomplete mineralization. Being a source of osteogenic cells [41], a lot of vessels were observed in the new tissue. In comparison to the hosting bone, the new bone tissue had a large amount of osteoblasts participating in remodelling of the newly-formed bone tissue.

After implantation, the samples (b), (d) did not reveal osteoconductive properties, and the connective-tissue capsule was formed around the implant. Although the composite materials (b and e) contained the same components, the composite (b) was introduced as a powder, the composite (a) - as a sponge. Slow biodegradation was observed for both cases. Given that porosity of the samples was sufficient, degradation of the properties may be explained by increased density. This feature may slow down or even prevent the vascular ingrowth, therefore, osteogenic elements slowly penetrate the defect zone [42].

As the composites (a), (c), (e) were introduced into the bone defect, there was no any sign of inflammation in the implantation zone and in neighbouring tissues by the 21 st day. The biocompatibility of the composites with bone tissue was observed. Full biodegradation of the introduced composites takes place here, as well. Formation of a tubular-bone tissue at such an early stage of implantation indicates the apparent reparative and haemostatic features of the composites. 


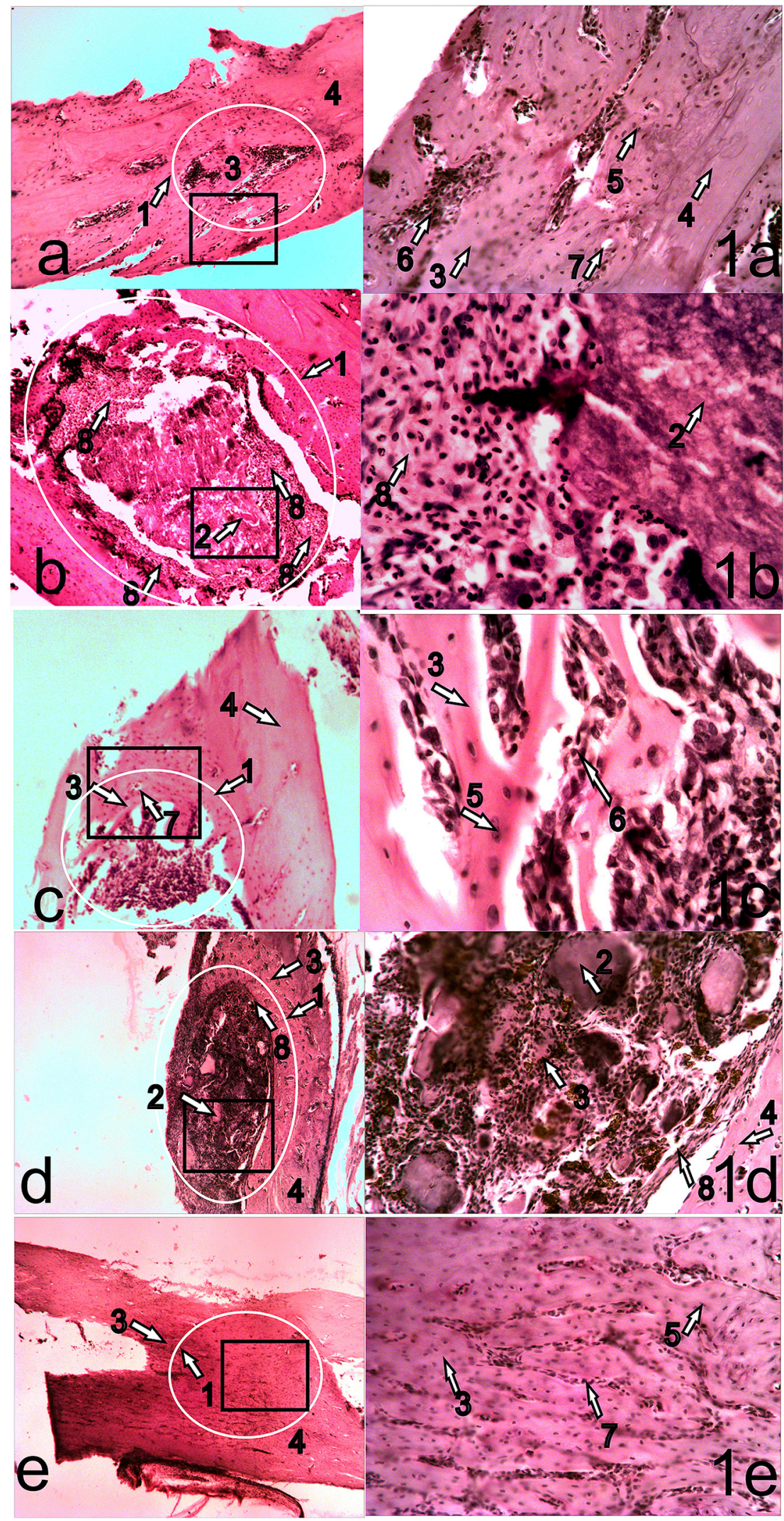

Fig. 6. Implant site after 3 weeks of implantation: (a, 1a) HA-Gel-ZrO magnification $\times 200$ of rectangular area). 1 is a defect zone, 2 is an implant, 3 is a newly-formed bone, 4 is a hosting bone, 5 are osteocytes, 6 is intertrabecular space, 7 are vessels, 8 is a connective-tissue capsule. 


\section{Conclusions}

The study concerns comparison of the HA and gelatine based composite materials obtained via ultra-sound mixing and in situ coprecipitation from aqueous solutions. Some materials like a) HAGel- $\mathrm{ZrO}_{2}$, c) HA-Gel-Ag, e) HA-Gel have biodegradation and reveal osteoconductive features. This allows considering both methods as appropriate for apatite formation. Formation of the composites by co-precipitation of HA with gelatine gives porous, biocompatible, biodegradable HA-Gel-Ag and HA-Gel materials. The calculated porosity of the obtained materials was about 75-80\% which corresponds to the porosity of a spongy bone.

\section{References}

[1] N. Zethraeus, F. Borgstorm, O. Strom, J.A. Kanis, B. Jonsson, Cost-effectiveness of the treatment and prevention of osteoporosis - a review of the literature and a references model, Osteoporos. Int. 18 (2007) 9-23.

[2] Y. Zhou, Y. Zhao, L. Wang, L. Xu, M. Zhai, S. Wei, Radiation synthesis and characterization of nanosilver/gelatine/carboxymethyl chitosan hydrogel, Radiat. Phys. Chem. 81 (2012) 553-560.

[3] T.M. Keaveny, E.F. Morgan, G.L. Niebur, O.C. Yeh, Biomechanics of trabecular bone, Annu. Rev. Biomed. Eng. 3 (2001) 307-333.

[4] C. Kailasanathan, N. Selvakumar, V. Naidu, Structure and properties of titania reinforced nano-hydroxyapatite/gelatine bio-composites for bone graft materials, Ceram. Int. 38 (2012) 571-579.

[5] C. Rey, C. Combes, C. Drouet, M.J. Glimcher, Bone mineral: update on chemical composition and structure, Osteoporos. Int. 20 (6) (2009) 1013-1021.

[6] Z. Babaei, M. Jahanshahi, S.M. Rabiee, The fabrication of nanocomposites via calcium phosphate formation on gelatin-chitosan network and the gelatin influence on the properties of biphasic composites, Mater. Sci. Eng. C 33 (2013) 370-375.

[7] Y.S. Pek, S. Gao, M.S.M. Arshad, K.J. Leck, J.Y. Ying, Porous collagen-apatite nanocomposite foams as bone regeneration scaffolds, Biomaterials 29 (2008) 4300-4305.

[8] A.O. Elzoghby, Gelatin-based nanoparticles as drug and gene delivery systems: reviewing three decades of research, J. Control. Release 172 (2013) 1075-1091.

[9] A.O. Elzoghby, W.M. Samy, N.A. Elgindy, Protein-based nanocarriers as promising drug and gene delivery systems, J. Control. Release 161 (2012) 38-49.

[10] S. Kommareddy, D.B. Shenoy, M.M. Amiji, Gelatin nanoparticles and their biofunctionalization, in: C.S.S.R. Kumar (Ed.), Nanotechnologies for the Life Sciences, Biofunctionalization of Nanomaterials, vol. 1, WILEY-VCH Verlag GmbH \& Co. KGaA, Weinheim, 2005, pp. 330-352.

[11] S. Teng, L. Chen, Y. Guo, J. Shi, Formation of nano-hydroxyapatite in gelatin droplets and the resulting porous composite microspheres, J. Inorg. Biochem. 101 (2007) 686-691.

[12] R.K. Brundavanam, Z.-T. Jiang, P. Chapman, X.-T. Le, N. Mondinos, D. Fawcett, G.E.J. Poinern, Effect of dilute gelatine on the ultrasonic thermally assisted synthesis of nano hydroxyapatite, Ultrason. Sonochemistry 18 (2011) 697-703.

[13] T. Bera, A.N. Vivek, S.K. Saraf, P. Ramachandrarao, Characterization of biomimetically synthesized Hap-Gel nanocomposites as bone substitute, Biomed. Mater. 3 (2008) 025001.

[14] A. Haroun, V. Migonney, Synthesis and in vitro evaluation of gelatin/hydroxyapatite graft copolymers to form bionanocomposites, Int. J. Biol. Macromol. 46 (2010) 310-316.

[15] A. Shu, Y. Xianzhu, X. Zhangyin, X. Guohua, L. Hong, Y. Kangde, Synthesis and sintering of nanocrystalline hydroxyapatite powders by gelatin-based precipitation method, Ceram. Int. 33 (2007) 193-196.

[16] W.B. Hillig, Y. Choi, S. Murtha, N. Natravali, P. Ajayan, An open-pored gelatin/ hydroxyapatite composite as a potential bone substitute, J. Mater. Sci. Mater. Med. 19 (2008) 11-17.

[17] H.W. Kim, H.E. Kim, V. Salih, Estimulation of osteoblast responses to biomimetic nanocomposites of gelatin-hydroxyapatite for tissue engineering scaffolds, Biomaterials 26 (2005) 5221-5230.

[18] D.J. Balazs, K. Triandafillu, P. Wood, Y. Chevolot, C. van Delben, H. Harms, et al.,
Inhibition of bacterial adhesion on PVC endotracheal tubes by RF-oxygen glow discharge, sodium hydroxide and silver nitrate treatments, Biomaterials 25 (2004) 2139-2151.

[19] D.R. Monteiro, L.F. Gorup, A.S. Takamiya, A.C. Ruvollo-Filho, E. Rodrigues de Camargo, D.B. Barbosa, The growing importance of materials that preven microbial adhesion: antimicrobial effect of medical devices containing silver, Int. J. Antimicrob. Agents 34 (2009) 103-110.

[20] M. Kikuchi, T. Ikoma, S. Itoh, H.N. Matsumato, Y. Koyata, et al., Biomimetic synthesis of bone like nanocomposites using the self organization mechanism of hydroxyapatite and collagen, Compos. Sci. Technol. 64 (2004) 819-825.

[21] J. Guan, K.L. Fujimoto, M.S. Sacks, W.R. Wagner, Preparation and characterization of highly porous, biodegradable polyurethane scaffolds for soft tissue applications, Biomaterials 26 (2005) 3961-3971.

[22] N. Han, J.K. Johnson, P.A. Bradley, K.S. Parikh, J.J. Lannutti, J.O. Winter, Cell attachment to hydrogel-electrospun fiber mat composite materials, J. Funct. Biomater. 3 (2012) 497-513.

[23] V. Maquet, A.R. Boccaccini, L. Pravata, I. Notingher, R. Jérôme, Porous poly $(\alpha$ hydroxyacid)/Bioglass $\mathbb{B}$ composite scaffolds for bone tissue engineering. I: preparation and in vitro characterisation, Biomaterials 25 (18) (2004) 4185-4194.

[24] F. Naghizadeh, N. Sultana, M.R. Kadir, T.M. Shihabudin, R. Hussain, T. Kamarul The fabrication and characterization of PCL/rice husk derived bioactive glassceramic composite scaffolds, J. Nanomater. 2014 (2014) 1-9.

[25] F.H. Chung, Quantitative interpretation of x-ray diffraction patterns of mixtures, J. Appl. Crystallogr. 8 (1975) 17-19.

[26] F.S. Kaplan, W.C. Hayes, T.M. Keaveny, A. Boskey, T.A. Einhorn, J.P. Iannotti, Form and function of bone, in: J.A. Buckwalter, T.A. Einhorn, S.R. Simon (Eds.) American Academy of Orthopaedic Surgeons, Rosemont, IL, USA, 1994, pp. 128-184.

[27] C. Kailasanathan, N. Selvakumar, Comparative study of hydroxyapatite/gelatin composites reinforced with bio-inert ceramic particles, Ceram. Int. 38 (2012) 3569-3582

[28] W. Wei, R. Sun, Z. Jin, J. Cui, Z. Wei, Hydroxyapatite-gelatin nanocomposite as a novel adsorbent for nitrobenzene removal from aqueous solution, Appl. Surf. Sci. 292 (2014) 1020-1029.

[29] K. Mallikarjuna, G. Narasimha, G.R. Dillip, B. Praveen, B. Shreedhar, C. Sree Lakshmi, B.V.S. Reddy, B. Deva Prasad Raju, Green synthesis of silver nanoparticles using ocimum leaf extract and their characterization, Dig. J. Nanomater. Biostruct 6 (2011) 181-186.

[30] M.C. Chang, C.C. Ko, W.H. Douglas, Preparation of hydroxyapatite-gelatin nanocomposite, Biomaterials 24 (17) (2003) 2853-2862.

[31] B. Bracci, Gelatin-modified biomimetic apatite coatings, J. Biomater. Nanobiotechnol. 3 (2) (2012) 154-162.

[32] F. Wang, E. Guo, E. Song, P. Zhao, J. Liu, Structure and properties of bone-likenanohydroxyapatite/gelatin/polyvinyl alcohol composites, Adv. Biosci. Biotechnol. 1 (2010) 185-189.

[33] K.H.O. Pelkonen, H. Heinonen-Tanski, O.O.P. Hanninen, Accumulation of silver from drinking water into cerebellum and musculus soleus in mice, Toxicology 186 (2003) 151-157.

[34] ATSDR Toxicological profile for silver, Agency for Toxic Substances and Disease Registry, US Department of Health and Human Services, Public Health Service, Atlanta, GA, 1990.

[35] L. Fewtrell, Silver: Water Disinfection and Toxicity Spring, 2014, p. 50.

[36] G. Thrivikraman, G. Madras, B. Basu, In vitro/In vivo assessment and mechanisms of toxicity of bioceramic materials and its wear particulates, RSC Adv. 4 (2014) 12763-12781.

[37] T. Vagkopoulou, S.O. Koutayas, P. Koidis, J.R. Strub, Zirconia in Dentistry: Part 1. Discovering the nature of an upcoming bioceramic, Eur. J. Esthet. Dent. 4 (2) (2009) 130-151.

[38] A. Plut, Š. Sprogar, G. Drevenšek, S. Hudoklin, J. Zupan, J. Marc, M. Drevenšek, Bone remodeling during orthodontic tooth movement in rats with type 2 diabetes, Am. J. Orthod. Dentofac. Orthop. 148 (6) (2015) 1017-1025.

[39] K. Jahan, M. Tabrizian, Composite biopolymers for bone regeneration enhancement in bony defects, Biomater. Sci. 4 (1) (2015) 25-39.

[40] L. Geris, et al., Angiogenesis in bone fracture healing: a bioregulatory model, J. Theor. Biol. 251 (2008) 137-158.

[41] C.G. Chung, A.W. James, G. Asatrian, L. Chang, A. Nguyen, K. Le, et al., Human perivascular stem cell-based bone graft substitute induces rat spinal fusion, Stem Cells Transl. Med. 3 (10) (2014) 1231-1241.

[42] W. Jing, A.A. Smith, B. Liu, J. Li, D.J. Hunter, G. Dhamdhere, B. Salmon, et al., Reengineering autologous bone grafts with the stem cell activator WNT3A Biomaterials 47 (2015) 29-40. 